\title{
Preface
}

The emergence of the new marketing environment affects marketing/business science and practice (Kotler, 2011) in which the traditional marketing principle is influenced by the emergence of the electronic commerce applications such as Apps. E-commerce is a form of trade that has gained increasing attention from consumers and sellers; however, despite high growth rates, E-Commerce still has low levels of consumers (Rezaei et al., 2016). "E-commerce is defined as the process of buying and selling over the Internet" (Ramayah et al., 2009, p. 1223) and the process might include several online transactions like retailing, banking, tourism, and stock trading. As such "Apps commerce is a series of business efforts in utilizing apps for the distribution of information, sustaining and conducting relationships, communications, and transactions within an individual organization" (Rezaei et al., 2016, p. 409). Apps-commerce has deeply altered the way in which individual consumers conduct their business activities as the E-commerce is defined as the usage of the Internet to sell products or services to consumers.

Apps commerce have grown to be progressively efficient in a series of aspects along with the highest feature that is the performance along with accuracy and reliability involving transferring information. The E-commerce has advantages such as decreasing business transaction costs and also saving time, which makes it more feasible and effective. Apps and the related technologies are the platforms, through which organizations are struggling to implement their core business activities. Semantic Web, Internet of Things, Web 2.0, Web 3.0, Web mining, Social Computing, and Cloud Computing technologies, as a medium in Apps, empower organizations by providing a wider stand to information which is related to firm offering/products and services. Therefore, the traditional retail channel, as well as online direct channel, are dual channels in which recently, producers are progressively selling their products due to the establishment of the Internet.

Furthermore, Apps-Management is involved with business approaches via executing Apps in organizations to create and to enhance the communications channels, the Apps experience and distribution of information, to sustain and to conduct the relationships with stakeholders that are aiming for strategic results. 
This new phenomenon of E-commerce is becoming a strategic tool to enhance the firm's total value chain in business domains such as education, IS, IT, marketing, hospitality, tourism, education, and even human resource management. Apps-Commerce business models, includes Apps-Intermediaries, Apps-Auction, Apps-Game, Apps-Tourism, Apps-Product, Apps-Dating, and so on and so forth. Accordingly, Apps-Commerce management includes several aspects of a business, including Apps-CRM, Apps-HRM, Apps-Marketing, Apps-Advertising, AppsRetailing, Apps-Telecommunication, Apps-Security, Apps-Privacy, Apps-Cyber Law, Apps-Services, Apps-Location Map, Apps-Banking, and Apps-Payment. A successful management of Apps utilization is supposed to enhance E-commerce transactions in real-time. As a result, this book discusses trends, issues, and implications in Apps-Commerce development, implementation, and management as new phenomena of E-Commerce.

This book aims to contribute high-quality and original works that are highlighting the most important research topics, concepts, trends, issues, and practice implications in Apps-commerce development, implementation, and management. Throughout different discipline of business management, the book offers profound theoretical and practical foundations, regarding the current and future implementation of Apps-Commerce. The book would serve as a source of knowledge for researchers, educators, students, and industry practitioners all around the world.

\section{THE CHALLENGES}

E-Commerce advancement shifts the power of the supplier to the consumer, which contributes to important changes in the way firms relate to their clients and compete with each another; thus, there are no difficulties for customers to shift to an alternative online retailer if the performance of that retailer in unacceptable. Additionally, the emerging influence of the internet considerably magnifies the scope and impact of "sensory satisfactions" in marketing management (Achrol \& Kotler, 2012; Holbrook \& Schindler, 2003). Although some researchers advocated the importance of online experience in a commercial context and some others claimed that online experience is irrelevant for marketing, empirical evidence for these claims is lacking (van Noort et al., 2012). As such, consumers' churn behavior is an issue to be considered for businesses (Heinemann \& Schwarzl, 2010) and the management of customer's Apps churn behavior or turnover is one of the top agenda for marketing managers within industries. This sensory experience and satisfaction might control individual Apps patronage intention. In the mobile environment, (See-To et al., 2012) it was found that sensory experience is a significant element for the enjoyment and engagement with the video. For an Apps market, the sensory shopping experience 
should be perceived (Rosen \& Purinton, 2004), in which the motivation for sensual satisfaction during the shopping process must not be overlooked.

Despite the fact that the overall marketing cost is high (Copeland, 1923), in the time of recession, marketers should understand that the customer will reduce spending and relatively, companies will cut the marketing budgets (Kotler \& Caslione, 2009; Shankar et al., 2011). Specifically, churn issue and management of churn behavior is a fundamental concern for businesses with the emergence of the digital economy (Lejeune, 2001). Churn behavior has become an issue and is considered as one of the primary challenges that many retailers and organizations have to face, globally (Yu et al., 2011). The churn behavior rate in saturated markets (churn rates: the percentage of customers quitting their relationship with a company) might be more than 30\% per year (Zorn et al., 2010), thus, retailers should acquire new customers continually to survive in the market. For this reason, as Apps markets become totally and dramatically saturated, firms have confirmed that their key strategies should focus on recognizing those consumers who are likely to churn and shift to another Apps supplier.

\section{SEARCHING FOR A SOLUTION}

More experienced Apps users might find the Apps commerce interface as more predictable, quicker and easier to use compared to inexperienced online shoppers (McGoldrick et al., 2008), thus, it is crucial for online retailers to recognize that a customer's experience is not only limited to their interaction in the store. It has been documented that "for every four purchases made through the Internet, at least one results in dissatisfaction" (Cristiane \& Daniel, 2011) and only a very small minority of website visitors return to make purchases (Harris \& Goode, 2004). Virtual environments using Apps can generate changes in the affective states of consumers, influencing consumer's attitude toward the firm and their participation in value creation. Kotler (1965) believes that some of the major features of the marketing environments could be usefully deployed in computer model terms. As the role of the technology continues to increase (Becerra et al., 2013; Drucker, 1966, 1967), studies of online commercial retail are crucial to academic research (Allen et al., 2006).

Small businesses and large corporations spend a substantial amount of budget a year, yet many of these businesses fail to reach the organization's goals and are uncertain how to use this technology to gain competitive advantage or market advantages (Bevan \& Murphy, 2001; Lam et al., 2004). According to Bulu (2012), throughout the evolution of the web, the focus has moved from "access and find" (Web 1.0), "share, participate, and collaborate" (Web 2.0) to "immersive collaboration and co-creation" (Web 3.0). Moreover, regarding the evolution of information 
technology, the attractiveness of immersive online settings revolutionizing the expression of human behaviors (Guitton, 2012), which intensifies retail competition, needs more sophisticated management practices.

\section{ORGANIZATION OF THE BOOK}

The book is organized into 14 chapters. A brief description of each of the chapters follows:

Chapter 1 discusses on Social Mobile Analytics and Cloud and introduces SMAC as a new abbreviation that every business leader is thinking off. SMAC technologies are creating enormous opportunities across industries while the consumer willingly gives up personal information. Cloud technologies have made it possible to collect and store such large amounts of data. While each of these four technologies is able to enhance the business on its own, using these four technologies together as a stack has changed the way businesses are looking to maximize their customer base, enhance brand value and off course, increase company profit. The objective of this chapter is to provide an overview of SMAC. The importance of implementing SMAC in a business to remain competitive in the future will be emphasized. The different technologies will be introduced, and the benefits and opportunities of SMAC trends will be pointed out. The solution and recommendation, future research directions, and conclusion follow this section.

Chapter 2 discusses applications in the marketing evolution from social networks to mobile social networks. Digital marketing has put mobile and social into the center of the vision. Mobile and social interactions have transformed marketing activities and imposed a new paradigm on consumer behaviors based on real-time customer relationship management, peer-to-peer social influence and idea co-creation with consumers. Extensive research has been conducted in both mobile and social media domain, however, few types of research have led a systematic approach by illustrating the marketing evolution and identifying mobile and social features. In this chapter, authors fill this research gap through a literature review approach by first presenting the new marketing paradigm created by social networks, and then analyzing the marketing evolution from web-based social networks to mobile social networks. The mobile and social features are identified to guide marketers for application design. Finally, four case studies are presented to show how these features are distributed in applications to lead a better consumer experience. This chapter brings both theoretical and practical implications in this new trends.

Chapter 3 discusses the Apps-commerce in emerging markets and provides insights and future business models perspectives. The Internet and Apps related technologies are considered as information "super highway" since they are able to connect 
people, computers, and data to one another. Because of them, a new communication medium has risen, which provides an access to the large flow of information across various broad extensions. As a consequence, there has been a need for understanding the behaviors of online consumers, since Information Technology and its usage have had a massive impact on shopping behaviors as well as the rate of market success. Therefore, this chapter's aim will be to sanitize the current understanding of Apps/ online consumer behavior to shape Apps marketing strategies and implementations.

Chapter 4 discusses the Security Problems in Cloud Computing Environments using Deep Analysis and a Secure Framework. Cloud computing technology is a relatively new concept of providing scalable and virtualized resources, software and hardware on demand to consumers. It presents a new technology to deliver computing resources as a service. It offers a variety of benefits like services on demand and provisioning and suffers from several weaknesses. In fact, security presents a major obstacle in cloud computing adoption. In this chapter, authors discussed security problems in cloud computing systems and show how to solve these problems using a quantitative security risk assessment model named Multi-dimensional Mean Failure Cost (M2FC). In fact, this chapter presents first a deep analysis of security issues related to cloud computing environments and then propose a generic framework that analysis and evaluate cloud security problems and then propose appropriate countermeasures to solve these problems.

Chapter 5 discusses how cross-platform technology can facilitate the easier creation of business Apps. Applications for mobile devices - apps - have seen unprecedented growth in importance. Ever better apps keep propelling the proliferation of mobile computing. App development is rather easy, particularly if it is based on Web technology. However, implementing apps that are user-friendly and useful in the long-run is cumbersome. Thereby, it typically is expensive for corporate developers. Nonetheless, business apps are embraced by enterprises. To overcome the overhead of developing separately for multiple platforms and to mitigate the problems of device fragmentation, cross-platform development approaches are employed. While many such approaches exist, few have found widespread usage. In this chapter, authors argue what the path towards future solutions could look like. They thereby take a rather technological look, but always keep business-orientation in mind. Their findings suggest that much effort is needed to enable the next generations of business apps. However, such apps will provide many merits and possibilities. Moreover, they provide the chance to master several of today's challenges.

Chapter 6 elaborates on the essential of Apps marketing implementation and Ecommerce strategies and discusses Apps users' decision-making process. Consumer behaviors and attitudes represent a continuously evolving field, thus, by understanding consumer behavior towards Apps from marketing strategy standpoint, managers can benefit from acquiring much information from applying and translating new insights 
into strategies and tactics that could be helpful for retailer's decision makers. This chapter mainly proposed an integration of Internet consumer attitudes, behavior and Apps marketing strategy. This chapter is twofold in terms of having implications both in theory and practice. Indeed, this study helps in understanding consumer decision-making process in Apps environment and produce new knowledge to online and Apps retailers, marketing managers as well as marketing and IT scholars. The Apps related technologies have developed as an important medium for marketing in various areas, including expanded geographic scope, novel opportunities for appreciating customers and offering cost efficiencies.

Chapter 7 discusses Mobile Social Commerce. S-commerce and M-commerce become buzz word recent years. The social and mobile elements have brought new ways of thinking as well as challenging opportunities in e-commerce. In this chapter, authors firstly introduce the concepts of online social commerce, its classifications, and social shopping behaviors. Secondly, they analyze the evolution from online social commerce to mobile social commerce. Different case studies are given to demonstrate the concept of mobile social commerce, to precisely define how mobile and social feathers add value to traditional e-commerce.

Chapter 8 discusses on brand personality, social status and physical vanity in building luxury fashion branded Apps. While there have been an increasing number of researches done on branding and consumer behavior especially on brand personality, social status and vanity and its influence on purchase intention, there are little studies that focus on the influence of all these factors collectively on Apps purchase intention. This chapter conceptually argues that brand personality, social status, and physical vanity are important in building luxury fashion branded Apps. While brand personality and luxury fashion branded Apps as an internal factor plays an important role in deciphering if it has an influence on an individual's Apps purchase intention for luxury fashion brands; therefore, it is important to look into how external factors have an influence on an individual.

Chapter 9 discusses on post-purchase apps usage attitudes to revisit trust, customer satisfaction and loyalty of apps usage. The importance of the relationship between customer and retailer has become prevalent in the ever-increasing competitive online market. The customers buying process often begin with the downloading of the required Apps in relation to the products they intended to purchase. Hence, customer satisfaction depends on customers' post-purchase evaluation on their experience with the use of the Apps. The aim of this chapter is to conceptualize the usage of the Apps for online shopping, by examining the role of trust and satisfaction gained from the market interaction between the customers and retailers. Customers rely heavily on the information as well as the experiences encountered from the use of the apps. The retailers need to gain insights from the customer's perspective on the 
usage of the app in order to improve customer relationship. This has an impact on retailers' marketing efforts for winning the customers' loyalty.

Chapter 10 discusses Apps in hospitality and tourism to conceptualize branded Apps in building traveler satisfaction and loyalty. The development of Apps usage in the tourism industry is along with the rise of relevant technologies that has affected the tourism industry all around the world. In order to build a competitive brand, firms are forced to implement the information technology related functions in their core business model. This chapter mainly focuses on the impact of Apps implementation in hospitality and tourism sector and conceptually propose that how branded Apps could yield tourist satisfaction and loyalty. Apps awareness, Apps quality, and Apps image are proposed as several indicators of traveler's satisfaction and loyalty. The chapter argues that branding makes a business advantage; the brand follows the indication of quality and assurance to the buyer and also special characteristics that could inspire consumers to buy products or services that are branded.

Chapter 11 discusses augmented reality apps for tourism destination promotion. This chapter focuses on the effectiveness of Augmented Reality (AR) supported applications for mobile and wearable devices during the visitation of tourist destinations. AR as an innovative technology tool becomes an inseparable part of destinations' marketing in different countries across the world. However, the use of AR for marketing purpose in tourism destinations is fully dependent on access and resource availabilities. Hence the effective of AR application in tourism destination marketing remains a subject to detailed and accurate information availability of a particular destination or a region. This chapter draws particular reference to the AR supported 'Mobile guides' that replaced conventional human tourist guides. The chapter is indebted to AR literature written Turkish. Results demonstrate that $\mathrm{AR}$ as an innovative technology can be applied for tourism destination promotion.

Chapter 12 proposes antecedents of apps channel selection in form of a research proposal. Hence, this chapter aims to propose a research proposal in the determinants and the factors influencing App channel selection. It is essential to building an understanding of concepts of social enterprise regarding the Apps marketing and to design an empirically based research to cultivate an understanding in terms of the perceptions and practices of Apps enterprises within the context of marketing. The significance of this research is to provide the undergraduate researcher a guideline in proposing a research and forming strategic marketing and tactical decision-making when defining the roles of Apps channel.

Chapter 13 proposes value and risk as the dual pillars of apps usefulness. The rapid expansion of Apps and subsequently Apps marketing have now entered into a post-adoption stage, where technical characteristics and qualities such as visual design, user interfaces, and navigation become the determinants of consumer's intentions. However, very few studies have looked into the perceptions related to 
usefulness and "post-adoption" or acceptance of Apps-commerce. Building on risk and value concept, the aim of this chapter is to expand an understanding of the decision-making of those potential Apps customers to adopt Apps usage for the first time and also re-purchase decisions of experienced e-customers. As the concept of customer value has received increasing attention from both marketing, managers, researchers and practitioners, more originalities are encouraged to start incorporating the elements of Apps value, Apps risk, Apps usefulness elements in their strategies to sustain their core businesses activities. Besides, customers are likely to perceive a higher level of risk in using Apps than in traditional in-store setting. Thus, this chapter proposes that the risk concern of user information given to the vendors has an impact on the amount of consumption in Apps market. The practical and conceptual implications are discussed.

Chapter 14 finalizes the book by proposing the future of apps as a smart investment for business. Today consumers are demanding apps that can fulfill many different needs and are much more individualized. This high and consuming demand forces the developers the use large amounts of data before they can be able to meet these needs. The objective of this chapter is to look at the implications apps have on society. Current apps are not going to be around forever, so future potential modifications will be discussed as changes are needed to keep the users engaged. Benefits, challenges, and solutions will be discussed along with examples.

Sajad Rezaei

Taylor's University, Malaysia

\section{REFERENCES}

Achrol, R., \& Kotler, P. (2012). Frontiers of the marketing paradigm in the third millennium. Journal of the Academy of Marketing Science, 40(1), 35-52. doi:10.1007/ s11747-011-0255-4

Allen, G. N., Burk, D. L., \& Davis, G. B. (2006). Academic data collection in electronic environments: Defining acceptable use of internet resources. Management Information Systems Quarterly, 30(3), 599-610.

Becerra, E. P., Badrinarayanan, V., \& Kim, C.-H. (2013). Influence of thinking tendencies on online transaction of hybrid retailers. Journal of Business Research, 66(3), 336-344. doi:10.1016/j.jbusres.2011.08.014

Bevan, J., \& Murphy, R. (2001). The nature of value created by uk online grocery retailers. International Journal of Consumer Studies, 25(4), 279-289. doi:10.1046/ j.1470-6431.2001.00195.x 
Bulu, S. T. (2012). Place presence, social presence, co-presence, and satisfaction in virtual worlds. Computers \&amp. Education, 58(1), 154-161. doi:10.1016/j. compedu.2011.08.024

Copeland, M. T. (1923). Relation of consumers' buying habits to marketing methods. Harvard Business Review, 1(3), 282-289.

Cristiane, P. S., \& Daniel, V. H. F. (2011). Perceptions of justice after recovery efforts in internet purchasing: The impact on consumer trust and loyalty toward retailing sites and online shopping in general. Brazilian Administration Review, 8(3), 225-246. doi:10.1590/S1807-76922011000300002

Drucker, P. F. (1966). What computers will be telling you. Management Review, 55(10), 30.

Drucker, P. F. (1967). The manager and the moron. Management Review, 56(7), 20.

Guitton, M. J. (2012). Living in the hutt space: Immersive process in the star wars role-play community of second life. Computers in Human Behavior, 28(5), 1681-1691. doi:10.1016/j.chb.2012.04.006

Harris, L. C., \& Goode, M. M. (2004). The four levels of loyalty and the pivotal role of trust: A study of online service dynamics. Journal of Retailing, 80(2), 139-158. doi:10.1016/j.jretai.2004.04.002

Heinemann, G., \& Schwarzl, C. (2010). New online retailing — what does it mean?. In New online retailing (pp. 19-91). Gabler.

Holbrook, M. B., \& Schindler, R. M. (2003). Nostalgic bonding: Exploring the role of nostalgia in the consumption experience. Journal of Consumer Behaviour, 3(2), 107-127. doi:10.1002/cb.127

Kotler, P. (1965). The competitive marketing simulatora new management tool. California Management Review, 7(3), 49-60. doi:10.2307/41165632

Kotler, P. (2011). Reinventing marketing to manage the environmental imperative. Journal of Marketing, 75(4), 132-135. doi:10.1509/jmkg.75.4.132

Kotler, P., \& Caslione, J. A. (2009). How marketers can respond to recession and turbulence. Journal of Customer Behaviour, 8(2), 187-191. doi:10.1362/147539209X459804

Lam, S., Shankar, V., Erramilli, M. K., \& Murthy, B. (2004). Customer value, satisfaction, loyalty, and switching costs: An illustration from a business-to-business service context. Journal of the Academy of Marketing Science, 32(3), 293-311. doi:10.1177/0092070304263330 
xxiv

Lejeune, M. A. (2001). Measuring the impact of data mining on churn management. Internet Research, 11(5), 375-387. doi:10.1108/10662240110410183

McGoldrick, P. J., Keeling, K. A., \& Beatty, S. F. (2008). A typology of roles for avatars in online retailing. Journal of Marketing Management, 24(3/4), 433-461. doi:10.1362/026725708X306176

Ramayah, T., Rouibah, K., Gopi, M., \& Rangel, G. J. (2009). A decomposed theory of reasoned action to explain intention to use internet stock trading among malaysian investors. Computers in Human Behavior, 25(6), 1222-1230. doi:10.1016/j. chb.2009.06.007

Rezaei, S., Shahijan, M. K., Amin, M., \& Ismail, W. K. W. (2016). Determinants of app stores continuance behavior: A pls path modelling approach. Journal of Internet Commerce, 15(4), 408-440. doi:10.1080/15332861.2016.1256749

Rosen, D. E., \& Purinton, E. (2004). Website design: Viewing the web as a cognitive landscape. Journal of Business Research, 57(7), 787-794. doi:10.1016/S01482963(02)00353-3

See-To, E. W. K., Papagiannidis, S., \& Cho, V. (2012). User experience on mobile video appreciation: How to engross users and to enhance their enjoyment in watching mobile video clips. Technological Forecasting and Social Change, 79(8), 1484-1494. doi:10.1016/j.techfore.2012.03.005

Shankar, V., Inman, J. J., Mantrala, M., Kelley, E., \& Rizley, R. (2011). Innovations in shopper marketing: Current insights and future research issues. Journal of Retailing, 87. Supplement, 1(0), S29-S42. doi:10.1016/j.jretai.2011.04.007

van Noort, G., Voorveld, H. A. M., \& van Reijmersdal, E. A. (2012). Interactivity in brand web sites: Cognitive, affective, and behavioral responses explained by consumers online flow experience. Journal of Interactive Marketing, 26(4), 223-234. doi:10.1016/j.intmar.2011.11.002

Yu, X., Guo, S., Guo, J., \& Huang, X. (2011). An extended support vector machine forecasting framework for customer churn in e-commerce. Expert Systems with Applications, 38(3), 1425-1430. doi:10.1016/j.eswa.2010.07.049

Zorn, S., Jarvis, W., \& Bellman, S. (2010). Attitudinal perspectives for predicting churn. Journal of Research in Interactive Marketing, 4(2), 157-169. doi:10.1108/17505931011051687 